JULY I, I899.

THE MOSSBERG TIRE-BELL.

The tire-bell has now been used for no inconsiderable time, and seems to have met with the approval of most wheelmen. Like most bicycle appliances, the tire-bell has been so improved since its introduction that it bids fair to supplant the handle-bar bell. Among the improved forms should be mentioned bell made by the Frank Mossberg Company, of Attleboro, Mass., which embodies in its construction certain principles not uninteresting from the mechanic's stand point. The striking mechanisin of the Mossberg bell consists of two steel rods or hammers sliding freely in guides. By a revolving cam-shaft these hammers are caused to move alternately upward and strike the gong. Gravity and rebound bring these hammers gong. Gravity and rebound bring these hammers pelled upward by the rotation of the carn-shaft. The power required in ringing the bell overcomes only the weight of the hammers and the rotative friction of the caln-shaft. The caln-shaft with its friction whee is mounted radially to the axis of the bell. The bells are mounted on a stud and, together with the cainshaft, are swung in the main bracket by pulling on a cord, to bring the friction-wheel in contact with the tire.

\section{THE MOSASAURS}

The American Museum of Natural History has ac quired through its Curator of Vertebrate Palæontology, Prof. Henry F. Osborn, a remarkable example of an ancient marine lizard-if this term has a proper sig nificance in connection with these fossils-which was procured from its owner, Mr. Bourne, of Scott City, Kansas.

This unique object is now exhibited, properly framed and protected, on the walls of the hall way in the fourth story of the museum, and certainly produces a distinctly impressive realization of vanished faunal conditions on our earth. In a long sigmoidal curve, with its fore and hinder appendicular skeleton fully revealed, its lon skull in complete preservation, with a row of sanguinary teeth, and its tail almost fully shown, this sauria displays its proportions, the relations of its parts, and even meets, half-way, the pleased imagination of the spectator, by a simulated expression of ferocity and predaceous pursuit.

The Mosasaurs, to which this fossil belongs, are not novelties in the world of science, nor are their remains unusual. Hundreds of skeletons have been deposited in Yale College by Prof. Marsh, though more or less fragmentary. Prof. Cope possessed them in his cabinet the University of Kansas owns a long series of thei skeletons, and they have been exhumed from the Cretaceous beds of North and South America, New Zealand and Europe. As long ago as $\mathbf{1 7 8 0}$ the famous individual from the Maestricht beds in Holland was procured by Dr. Hoffinann, a surgeon, whose claims to its possession were disputed by a Canon of the Church. Finally, confiscated by this theologian, it became the interesting cause of a general order by becalne the interesting cause of a general order by the commander of the French troops in ing, upon his siege of this eity, that certain house contained the precious re mains, orders were given to avoid it demolition. Upon the entrance of the troops, however, the skull was not found. It had been removed. A promise of 600 bottles of wine for its recovery very quickly revealed its retreat, "for the next day a dozen grenadiers brought the specimen in triumph to the house of the representative, and it was subsequently conveyed to the museum in Paris." conveyed to the nuseum in Paris." Besides their numernus representations
in museums, Marsh, Cope, Goldfuss, Dallo, Boulenger, Owen, Baur, Williston, Hector, have studied and discussed their nature from the evidence of many othe specimens. The distinction of this example, here shown, is its remarkable completeness, for with the exception of a few digital bones and soine two feet of a lew digital bones and some two feetc These large swimming reptiles lived These large swimming reptiles lived
during the deposition of the Upper during the deposition of the Upper
Cretaceous, and seem, throughout their Cretaceous, and seem, throughout their
world-wide distribution, to have ranged world-wide distribution, to have ranged
within identical geological liwits. In within identical geological
this country they occur in the Cretaceous, in New Jersey, Wyoming Kansas, Alabama, Dakota. Their occurrence was a little earlier in America Zealand than in America, eading to the possible deduction that a center of radia tion way have been localized in the latter area.

The species here figured and exhibited at the museum is Tylosaurus prariger Cope,

\section{Srientific Americau.}

and belongs to one of the three great divisions into which the Mosasaurs, by Williston, have been conveniently grouped, viz., the Tylosaurinæ, the Platecarpinæ and the Mosasaurinæ, a division recognized under a different terminology by other investigators.

In Clidastes, as an example of the Mosasaurinæ, a slender and shorter body, powerful tail, numerous teeth, medium sized paddles, few phalanges, are dis tinguishing features. In Tylosaurus, greater length, sıall paddles, numerous'digits, slender head, sepa-

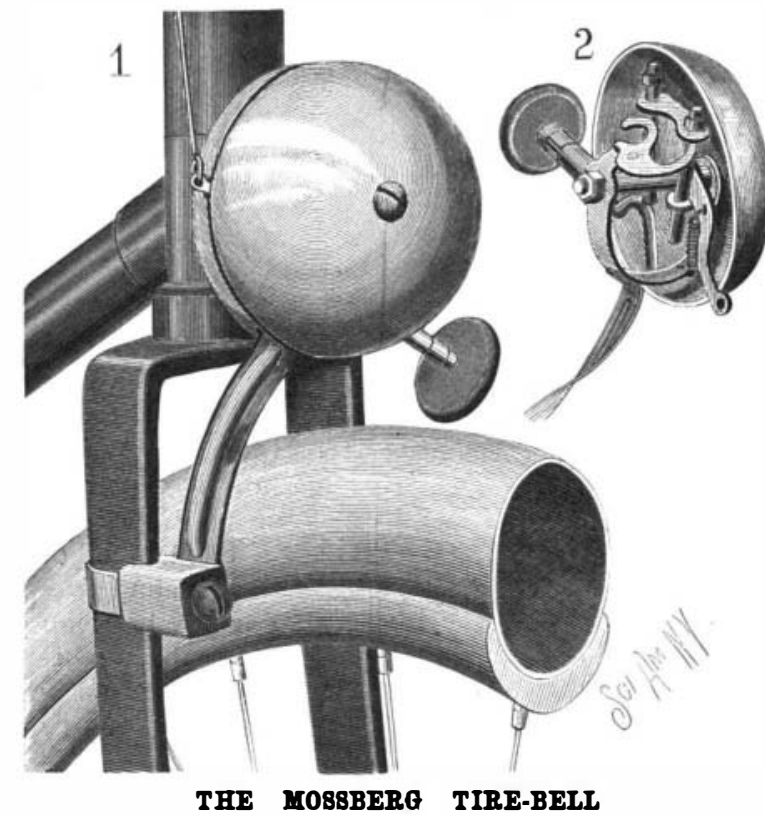

rate it superficially from its congeners. Platecarpus 1 believed by Williston to have been the monarch amone these marine monsters. combining flexibility and strength, with large paddles, broad skull, few and powerful teeth. The Tylosaurus probably furnished the largest individuals, though, in contrast to the sensational claims of some writers for a length of one hundred feet, their maximum size did not exceed fortyfive. These marine lizards were covered by a scaly bonized scales is on view in the museum of the Kansas bonized scales is on view in the museum of the Kansas did'not inhabit deep waters as the Plesiosaurs, but flourdid not inhabit deep waters as the Plesiosaurs, but flour-
ished in bays and estuaries, enjoying a rather narrow range of locomotion and feeding for the most part on fishes.

Two extracts respectively from Williston and Cope may suggestively close this brief description. "While the flexibility and loose union of the jaws doubtless permitted animals of considerable size to be swallowed, the structure of the pectoral girdle would never have permitted any such feats of deglutition of which the python and boa are capable python and boa are capable. -. . It has been sup posed that the prey, after seizure, was pulled dow the separated jaws. This, however, could not have been true. The mandibles in front, while not rigidly

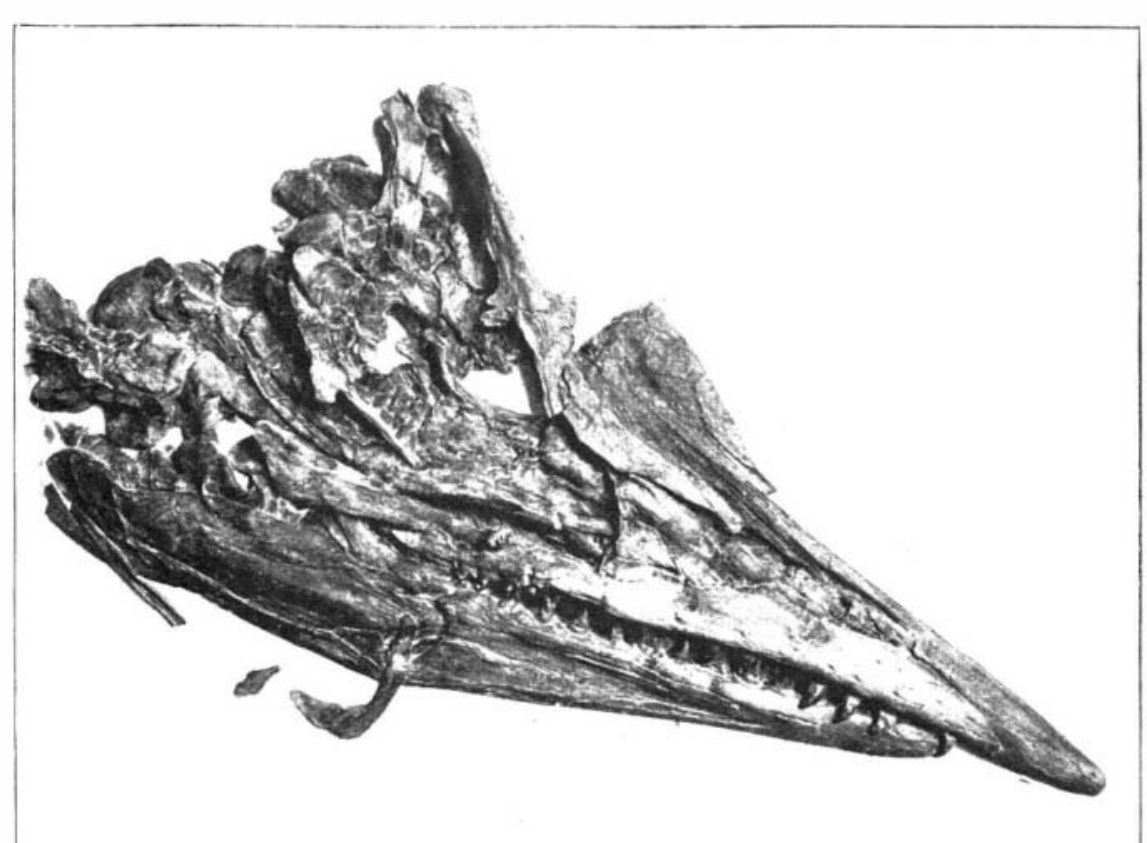

HEAD OF TYLOSAOROB connected, yet show ligamentous union, and the quadrates were largely fixed posteriorly. . . . Possibly a saurian of the largest size might have swallowed entire an animal as large as a two-year-old calf, but I doubt the possibility." The following more speculative statement is from Cope : "The habit of swallowing large bodies between the branches of the under jaw necessitates the prolongation forward of thic mouth of the gullet; hence the throat of the Mosasnur: must have been loose and almost as baggy as a pelican's. Next the same habit must have compelled the pipe, which is always in front of the gullet. Hence pipe, which is alirays in front of the gullet. Hence a hiss, as do animals of the present day which have a similar structure, as, for instance, snakes. Thirdly, the tongue must have been long and forked, and for this reason: Its position was still anterior to the glottis, so that there was no space for it, except it were in closed in a sheath beneath the windpipe, when at rest, or thrown out beyond the jaws, wherr in motion."

The eity and the public of New York are to be congratulated that so superb a specimen of these extinct water pythons can be seen in their Museum of Natural History. It is naturally and truly an object of intense interest.

The specimen itself came to the museum in a few large masses of chalk, from which it has been slowly developed by skilled workmen, revealing from day to day new indications of its perfection. It is stated by Prof. Osborn that cartilaginous supports of the trachea and some of the anterior ribs are retained in this skeleton, and that these vestiges will afford new or decisive evidence as to the zoological position of the Mosasaurs.

\section{Portable Museum for Scholara}

The Brooklyn Museum of Arts and Sciences has jus: purchased the first " musée scolaire" ever brought to this country. It consists of a system of charts devised by a French publisher of educational material. A sinall percentage of common school pupils ever visit the great natural history museums, or if they do, they are overwhelmed by the enormous bulk of the collecmuseum collection, and with a few trifling exceptions, the the botter. The portable exactly what they crave to know, and no pupil, however adverse to study and dry-as-dust subjects, would ever find a natural history lesson dull if it was illustrated by these charts. A whole set of charts can be purchased for less than $\$ 100$, and they will give the student a considerable grasp upon the subject, although, of course, the charts are necessarily elementary.

The charts or object cards, as they might be called, have actual samples of raw materials fastened to them. and other specimens, showing the various stages of manufacture, and finally the finished product. The various articles are wired to the charts and explanatory various articles are wired to the charts and explanatory
legends in French give the necessary description. Sowe of the charts are obtainable in English, and if there is a considerabl: demand for them, probably they will in: be published, with translations of the text. In the manufacture of linen, for example, specimens of flax are secured to the top, and the series is continued until finally the bleached or finished linen is represented by a small square of cloth. The chants a cloth. The charts are so portable that it would sect possible for the whole to school in country places, somewhat after the fashion of the traveling libraries, as there is almost no danger of breakage. In many out-of-the-way places where a knowledge of natural history and the arts is very limited, these systematic charts would be the entering wedge for much popular advancement of knowledge.

Bottle Closure cor Sterilized Liquids. For this purpose J. Every recommends a simple good cork stopper, which has been pierced by means of a redhot iron wire, almost from the middle of the side diagonally to the middle of the under side of the cork.

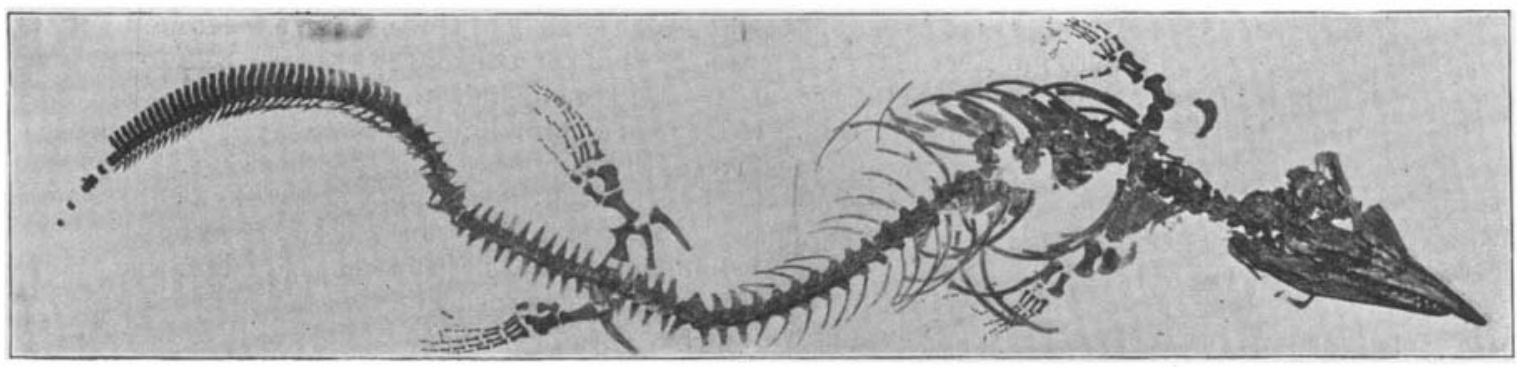
the cork on the bottle in the cork on the botte in opening is just above the neck of the bottle, thus allowing the air to escape. When the sterilization is finished, press the corls deeper into the neck of the bottle, producing in clos u re.-Pharmaceutica Zeitung. 